\title{
A social work study on the impact of age, gender and residential status on drug addiction
}

\author{
Mohammad Reza Iravani $^{\mathrm{a}}$, Karam Allah Javanmard ${ }^{\mathrm{b}^{*}}$, Shahram Basity ${ }^{\mathrm{c}}$, Faezeh Taghipour ${ }^{\mathrm{d}}$ and \\ Hajar Jannesari ${ }^{\mathrm{e}}$
}

\section{H R O N I C L E} \\ Article history: \\ Received October 8, 2012 \\ Received in revised format \\ 29 November 2012 \\ Accepted 22 December 2012 \\ Available online \\ December 272012 \\ Keywords: \\ Drug addiction \\ Social work study \\ Esfahan
}

${ }^{a}$ Assistant Professor, Department of Social Work, Islamic Azad University Khomeinishahr Branch, Daneshjou Blvd, Iran

${ }^{b}$ Assistant professor in Social work, University of Grand Ayatollah Brojerdi, Brojerd, Iran

${ }^{c}$ Phd, Department of Social Science, Payame Noor University/PO BOX 19395-3697 Tehran, Iran

${ }^{d}$ Assistant Professor, Department of Cultural Management Khorasgan (Isfahan) Branch, Islamic Azad University, Isfahan, Iran

${ }^{e}$ MS Student, Counseling Department, Islamic Azad University of Khomeinishahr, Khomeinishahr Branch, Daneshjou Blvd, Iran

\section{A B S T R A C T}

Drug addiction is one of the most important issues in developing countries and it has become a serious issue, which has impacted social health, significantly. In this paper, we study the relationship between age, gender and residential status with drug addiction. The study chooses a sample of 900 people where 450 were female, 450 were male, and all the residence lived in province of Esfahan, Iran. In our survey, two third of the surveyed people were living in cities and only one third of the surveyed people were residing in rural areas. The results of our survey have indicated that there were some positive relationship between age and addiction to drugs and between gender and addiction to drugs (Sig=0.04). In other words, older people will more likely to go for drug addiction. In addition, men tend to get addicted more than women do (Sig=0.03). However, there is no evidence to believe that residential status had any impact on addiction to drugs.

\section{Introduction}

Drug addiction is one of the most important issues in developing countries and it has become a serious issue, which has impacted social health, significantly. There are literally different studies to find the causes of drug addiction and possible remedy to cure addicted people (Heimburg \& Becker, 2002). Goldstein et al. (1996) investigated gender changes in manifestations of DSM-III-R antisocial personality disorder in 106 male and 34 female drug abusers enrolled in residential relapse prevention/health education treatment. They reported that addiction treatment programs required to look for gender differences in antisocial symptomatology in the development of individualized treatment programs for both male and female clients.

*Corresponding author. Tel:+ 989130758065

E-mail addresses: iravani@iaukhsh.ac.ir (M. R. Iravani) 
Forsyth et al. (2003) evaluated anxiety-related psychological risk factors such as anxiety sensitivity, and their relationships with drug of choice and addiction severity in an inpatient residential substance abuse population. They found no relationship between anxiety sensitivity and drug of choice, and reported that relationships between assessed psychological factors and domains of addiction severity were somewhat mixed.

According to Measham et al. (2011), there are some challenges for policy makers on how to address adult women's 'normalized' recreational drug use, in terms of a regime focused on educational provision focused at adolescent prevention; public health information designed for teenagers.

Pelissier et al. (2003) investigated gender similarities and differences in background personal characteristics, the effectiveness of treatment, and the predictors of post-release outcomes among incarcerated drug-using offenders. Their study revealed that in spite of the greater number of life problems among women than men, women had lower three-year recidivism rates and rates of postrelease drug implementation than did men. They also reported that for both men and women, treated subjects had longer survival times than those who were not treated. Differences in background characteristics and in factors associated with post-release outcomes for men and women recommended the plausibility of gender-specific paths in the recovery process.

Davis et al. (2002) investigated differences, including identification of comorbid factors and patients' perceived treatment requirements, between women in various SUD treatment settings including an intensive VA outpatient program and a private residential/outpatient program. In both settings the They reported women in VA SUD treatment experienced more impairment on factors of medical, psychiatric, and employment issues whereas the private agency sample maintained higher alcohol and family/social composite scores.

Delgado et al. (2008) investigated the association between acculturation and needle sharing among Puerto Rican injection drug users. They used Logistic regression techniques to study the relationship between place of birth, primary language spoken, primary residence of family and needle sharing for a sample of 200 Puerto Rican IDUs residing in Massachusetts by concentrating on quantitative findings. Their results indicated that Puerto Rican IDUs born on mainland USA were 2.1 times more likely to share needles than IDUs born in Puerto Rico, after controlling for gender, age, education, drug overdose, incarceration history and psychiatric status. In addition, their results indicated that Puerto Rican IDUs who were older had overdosed on drugs in the past year, had been incarcerated in their lifetime.

Mosavi et al. (2012) performed an investigation on the effect of emotional intelligence factors on recovering people addicted to drugs. They considered the impact of emotional intelligence (EQ) and the likelihood of recovery among addicted people who were under recovery treatments in three various groups in city of Esfahan, Iran including community-based treatment (CT) group, no support addictives (NA) and recovery center. They used two kinds of questionnaires including 90 questions with 15 scales and implemented a standard questionnaire to detect the likelihood of return to drug. The survey considered three samples of people from each three-drug recovery centers and performed regression analysis and reported that return to drug was inversely associated with being realistic (2.618), optimism (-2.409) and locus of control (-2.094).

In this paper, we present an empirical study to investigate the relationship between age, gender and residential status and drug addiction. The organization of this paper first presents details of the survey in section 2, section 3 explains results of our survey and the paper ends with some concluding remarks. 


\section{The proposed study}

In this survey, we study different personal and environmental characteristics, which influence people to go for drug addiction. The population of this survey includes two groups of people, where the first group includes all addicted people who have come to addiction treatment centers in province of Esfahan and the second group includes all non-addicted people who reside in city of Esfahan, Iran. We choose a sample of 900 people where 450 people are male, 450 people are female, and they are chosen based on simple random selection method. In our survey, two third of the surveyed people were living in cities and only one third of the surveyed people were residing in rural areas. The proposed study uses Zhang Anxiety Scale S.A.S (Zhang et al., 2012) to measure the anxiety among surveyed people.

There are 20 questions associated with the survey on the events passed during the previous week. In this survey, the people who have less anxiety receive fewer points and people with more anxiety receive more point. Overall, people who receive 25-44 points are categorized as normal people, people who have weak anxiety receive 45-59 points. In addition, people who receive 60-74 are suffering from anxiety and anyone who receives more than 75 points severely suffers from anxiety. The proposed study of this paper determines personal characteristics of addicted people in city of Esfahan, the relationship between educational backgrounds of addicted and non-addicted people and the relationship between the age of addicted and non-addicted people. In addition, study investigates the relationship between anxiety between addicted and non-addicted people and finally, the relationship between the level of social acceptance between addicted and non-addicted residence in city of Esfahan.

The following three hypotheses are considered for the proposed study of this paper,

1. There is a relationship between gender and attitude towards addiction.

2. There is a relationship between age and attitude towards addiction.

3. There is a relationship between residency location and attitude towards addiction.

\section{The results}

In this section, we present details of our findings to test three hypotheses of this survey.

\subsection{The relationship between gender and addiction}

The first hypothesis of this study investigates the relationship between gender and addiction. Table 1 demonstrates statistical observations between female and male participants.

Table 1

Statistical observations on the relationship between gender and addiction

\begin{tabular}{llllll}
\hline Age & Number & Mean & Standard deviation & Standard error & Sig. \\
\hline Female & 450 & 2.36 & 0.91 & 0.123 & 0.04 \\
Male & 450 & 3.64 & 0.96 & 0.136 & \\
\hline
\end{tabular}

As we can observe from the results of Table 1, there is a meaningful relationship between gender and drug addiction and the first hypothesis of this survey is confirmed. According the results of Table 1, men will be more likely to be toxicated by drugs. 


\subsection{The relationship between age and addiction}

The second hypothesis of this study investigates the relationship between age and addiction. Table 2 demonstrates statistical observations between low age people and high age people.

Table 2

Statistical observations on the relationship between age and addiction

\begin{tabular}{llllll}
\hline Age & Number & Mean & Standard deviation & Standard error & Sig. \\
\hline Low & 224 & 2.38 & 0.78 & 0.126 & 0.03 \\
High & 676 & 3.91 & 0.93 & 0.132 & \\
\hline
\end{tabular}

As we can observe from the results of Table 1, there is a meaningful relationship between age and drug addiction and the first hypothesis of this survey is confirmed. According the results of Table 1, as people get older, they will be more likely to be toxicated by drugs.

\subsection{The relationship between residential place and addiction}

The first hypothesis of this study investigates the relationship between residential place and addiction. Table 3 shows statistical observations between people who live in cities and rural areas.

Table 3

Statistical observations on the relationship between residential place and addiction

\begin{tabular}{llllll}
\hline Age & Number & Mean & Standard deviation & Standard error & Sig. \\
\hline City & 600 & 2.32 & 0.75 & 0.137 & 0.063 \\
Rural area & 300 & 3.67 & 0.84 & 0.130 & \\
\hline
\end{tabular}

As we can observe from the results of Table 3, there is not any meaningful relationship between residential place and drug addiction and the third hypothesis of this survey is not confirmed when the level of significance is five percent.

In summary, we can confirm that there is a relationship between people's age and gender and drug addiction but our survey did not enough evidence to believe residential place has any impact on drug addiction. The question is how to use social workers and specialists in different societies to setup some plans for preventing drug addiction and we believe any action could be executed through the following three steps as follows,

1. Prevention: This action is the cheapest and could be the most influencing part of practical action. There must be some bigger awareness on society about the bad consequences of drug addiction. In this regard, social workers and other professionals working with relevant organizations can act. Social workers and their role in building awareness and primary prevention programs can improve the status of professional workers in the country and improve their work performance. The scientific understanding of addiction and the factors affecting their attitudes towards their gender and age composition of addicted people in the community and workplace helps social workers setup better assistance programs. This could be accomplished through two various programs of public and specialize programs. Public programs cover total population or the population of a province, city or school etc. while special program is designed for people at risk such as children, parents or addicts and street children. Note that the purpose of this program is not to remove the entire drug addiction but we intend to reduce the number of people who are addicted to drugs and increase the average age of drug addiction.

2. The second level of prevention services for addicts: Whatever the initial prevention program is run again, the people will see that the use of drugs. Hence, the authorities should also provide specialized services and therapeutic measures to take possible action against drug 
addiction and there must be some institutions to operate using specialists such as psychiatrists, psychologists, doctors and social workers to serve people who were trapped in drugs. This could be accomplished through treating patience with more respect, asking their families to provide better assistance to help them quit drugs, characterizing biological, psychological and social factors of addicted people, etc.

3. The third level of prevention, Empowering and enabling: At this stage, the social worker should try to do these things: First, we need to explain for the patient that he/she did get addicted to drugs so that we could expect him/her to quit over a night. We need to provide working conditions for the addicted person when he/she quits, provide assistance by empowering him/her, etc.

One of the most important social tasks is to understand addiction and its characteristics. When a child or adult has a problem, others may work as an effective intervention. Unfortunately, in today's society, when a person is getting addicted to drugs, others stay away from this person, which could create more motivation for the addicted person for more isolation. We need to do the following to prevent children from drug addiction.

\section{Conclusion}

In this paper, we have presented an empirical investigation to study the relationship between gender, age, residential status on drug addiction. The study was established in province of Esfahan, Iran and there were 900 residences participated in our survey. The results of our survey have indicated that there were some relationship between age, gender and drug addiction but our survey did not find any evidence to conclude there were any relationship between residential place and drug addiction.

We have suggested a three stage program to setup an appropriate action to reduce drug addiction in this province. The first action, prevention, is the cheapest and could be the most influencing part of practical action. We have explained that there must be some bigger awareness on society about the bad consequences of drug addiction. In this regard, social workers and other professionals working with relevant organizations can act. Social workers and their role in building awareness and primary prevention programs can improve the status of professional workers in the country and improve their work performance.

The second stage of this program is associated with having more awareness among society. Hence, the authorities should also provide specialized services and therapeutic measures to take possible action against drug addiction and there must be some institutions to operate using specialists such as psychiatrists, psychologists, doctors and social workers to serve people who were trapped in drugs. Finally, the last step in our program is to provide working conditions for the addicted person when he/she quits, provide assistance by empowering him/her, etc.

\section{Acknowledgment}

The authors would like to thank the people who cordially participated in our survey trying to provide good assistance for accomplishing this survey. Special thanks to anonymous referees for their insights on earlier version of this work.

\section{References}

Davis, T.M., Carpenter, K.M., Malte, C.A., Carney, M., Chambers, S., \& Saxon, A.J. (2002). Women in addictions treatment: comparing VA and community samples. Journal of Substance Abuse Treatment, 23(1), 41-48. 
Delgado, M., Lundgren, L.M., Deshpande, A., Lonsdale, J., \& Purington, T. (2008). The association between acculturation and needle sharing among Puerto Rican injection drug users. Evaluation and Program Planning, 31(1), 83-91

Forsyth, J.P., Parker, J.D., Finlay, C.G. (2003). Anxiety sensitivity, controllability, and experiential avoidance and their relation to drug of choice and addiction severity in a residential sample of substance-abusing veterans. Addictive Behaviors, 28(5), 851-870.

Goldstein, R., Powers, S.I., McCusker, J., Mundt, K.A., Lewis, B.F., \& Bigelow, C. (1996). Gender differences in manifestations of antisocial personality disorder among residential drug abuse treatment clients. Drug and Alcohol Dependence, 41(1), 35-45

Heimburg, R. G. \& Becker, R. E. (2002). Cognitive-Behavioral Group Therapy for Social Phobia. New York, NY: The Guilford Press.

Measham, F., Williams, L., \& Aldridge, J. (2011). Marriage, mortgage, motherhood: What longitudinal studies can tell us about gender, drug 'careers' and the normalisation of adult 'recreational’ drug use. International Journal of Drug Policy, 22(6), 420-427.

Mosavi, S. E., Iravani, M. R., Nikbakht, A., Yazdi, E., \& Movahedie, A. (2012). A social work study on the effect of emotional intelligence factors on recovering people addicted to drugs. Management Science Letters, 2(7), 2311-2316.

Pelissier, B.M.M., Camp, S.D., Gaes, G.G., Saylor, W.G., \& Rhodes, W. (2003). Gender differences in outcomes from prison-based residential treatment. Journal of Substance Abuse Treatment, 24(2), 149-160

Zhang, C.Y., Jiang, Y., Yin, Q.Y., Chen, F.J., Ma, L.L., Wang, L.X. (2012). Impact of nurse-initiated preoperative education on postoperative anxiety symptoms and complications after coronary artery bypass grafting. The Journal of Cardiovascular Nursing, 27(1), 84-88. 